\title{
Characterization of Renal Stones by Computed Tomography and Ultrasound
}

\author{
Moawia Gamerddin ${ }^{1,2}$, Tommader Khider ${ }^{3}$, Ikhlas Abdelaziz ${ }^{3}$, Suliman Salih ${ }^{1}$, \\ Mohamed yousef ${ }^{3,4}$ \\ ${ }^{1}$ Taibah University, College of Medical Applied Sciences, Department of Diagnostic Radiologic Technology, \\ Fax: 8475790 P.O: 30001 Almadinah Almunawwarah, KSA \\ ${ }^{2}$ Alzaeim Alazhari University, Faculty of Radiological Sceinces and Medical Imaging.P.O.Box1432 Khartoum \\ Bahri 13311-Sudan \\ ${ }^{3}$ College of Medical Radiologic Science, Sudan University of Science and Technology. P.O.Box 1908, \\ Khartoum, Sudan \\ ${ }^{4}$ Radiologic technology department, college of applied medical science , Qassim university, Buraduh, KSA .
}

\begin{abstract}
This study aimed to evaluate the role of ultrasound(U/S) versus spiral Computed Tomography (CT) in the diagnosis of urinary system calculi. This study was conducted in the Department of Radiology in ALamal Hospital in Khartoum State, in the period ranged (August 2011- December 2011), included 50 subjects (35 males (70\%) and 15 females (30\%)), their ages range from 15 to 72 years old with symptoms of renal stones They were selected from patients who had been referred for CT KUB and U/S in ALamal hospital.Spiral CT and U/S were done for all cases .this study showed that The most affected age group ranged from 21-40 years old $56 \%$, most patients were affected in the both sides, with no history of renal stones in their families most of the stones lodged in the kedneys (36\%) and at the ureters (8\%). It can be said that the two image modalities were performed together and used as essential techniques of renal stones, which help to obtain accurate diagnosis and demonstrate any changes that can affect urinary systems by stones.
\end{abstract}

Key words Computed Tomography, Renal Stones, Ultrasound, spiral CT

\section{Introduction}

Urinary tract stones are common, with a lifetime incidence of up to $12 \%$ and recurrence rates of up to $50 \%$. In diagnostic and treatment algorithms, stone burden is the most important factor to consider and forms the basis of all clinical decision making [1].Thus, accurate measurement of all calculi is crucial. Since its introduction [2], unenhanced helical computed tomography (CT) has replaced intravenous urogram and is now regarded as the reference standard in the work-up of renal colic, owing to its high sensitivity and specificity. Apart from being the diagnostic standard, CT has the advantage of providing detailed anatomical information, can identify secondary signs of stone passage, and is useful for ruling out alternate pathologies in cases of diagnostic uncertainty. Despite the advantages of unenhanced CT, ultrasound (US) is also commonly used as a diagnostic tool in the management of urolithiasis. US is recognized to be both less sensitive and specific than $\mathrm{CT}$; however, it is commonly available, inexpensive to operate and poses no risk of radiation exposure. In many cases, renal and ureteric calculi are incidentally diagnosed in the workup of other conditions. It has been reported that US may detect stones as small as $0.5 \mathrm{~mm}$ under optimal conditions. For these reasons, some centers may still use US in the initial work-up of renal colic [3].Up to date, there has been little direct comparison of the accuracy and reliability of US compared with CT in sudan.Non-contrast spiral CT is presently more extensively used for the diagnosis of urolithiasis, especially in the setting of acute flank pain in adult patients. However, there is little data published over the use of spiral CT in pediatric urolithiasis. The presenting symptoms of children with stone disease are neither characteristic nor predictable and range from none to sepsis. Thus in pediatric patients with signs and symptoms suggestive of stone disease, radiologic studies are necessary for making an accurate diagnosis.Classically kidney, ureter and bladder plain films (KUB), ultrasound (US) and intravenous urography (IVU) have been utilized for this purpose. However, very little information exists in literature evaluating the accuracy of these modalities in the diagnosis of stones in the pediatric population. Given that the imaging of stones in children with conventional techniques has generally been non-satisfactory due to problems related to intestinal gas and smaller stone size in children, one may expect that spiral CT would be very beneficial for this age group.

This study aimed to evaluate the role of ultrasound versus spiral CT in the diagnosis of urinary system calculi.

\section{Materials \& Methods}

This study was performed in Department of Radiology in ALamal Hospital in Khartoum State, in the period ranged (August 2011- December 2011), included 50 subjects (36 male and 14 female) with age range between 
from 17 to 70. They were selected from patients who had been referred for CT KUB and U/S in ALamal hospital. The variables that collected from each subject include:, U/S findings ,CT findings, site of the stone ,gender, age , and body habitus

CT machine

The CT images were conducted using (TOSHIBA aquilion 64 slices) CT scanner. The scan parameter (3mm slice, $120 \mathrm{kvp}, 225 \mathrm{MAS}$ ). And with using the electronic caliper within the scanner the following diameters were measured. The features of CT scanner are:256 slices in one rotation with $.5 \mathrm{~mm}$ slice thickness Coverage of $13 \mathrm{~cm}$ in patient axis direction Advanced Sure Workflow software with PhaseXact Largest couch capacity in the industry $-180 \mathrm{~cm}$ long by $47 \mathrm{~cm}$ wide $40 \%$ dose reduction compared to previous models

\section{CT KUB technique}

CT KUB (non contrast enhanced CT of kidney, ureter and bladder) is useful to determine the number and location of urinary tract calculi. It is used in some centers as primary investigation of renal calculi.The patient lies supine on CT scanner table.Scout view was obtained. A low radiation dose technique is used to scan from the top of the kidney to include the bladder base with slice thickness of $5 \mathrm{~mm}$ or less as determine by CT saner (no use of i.v. contrast)

\section{U/S machine}

GE medical system LOQIC 5Expert ,made by yocogama medical systems .LTD -JAPAN - model 2302650 ,serial number 1028924,manufactured April 2005 ,Choice of transducer: -Use $3.5 \mathrm{MHz}$ for adults, curvilinear probe, $5 \mathrm{MHz}$ for children and thin adults. Setting the correct gain: -Start by placing the transducer longitudinal central and at the top of the abdomen (the xiphoid angle).Ask the patient to take a deep breath and hold it in. Angle the transducer beam towards the right side of the patient

\section{Abdomen U/S technique}

Patient should take nothing by mouth for 8 hours preceding the examination.If fluid is essential to prevent dehydration, only water should be given. Infants should be given nothing by mouth for 3 hours preceding the examination.

\section{Results}

This data shows U/S and CT finding included 50 patients analyzed in tables and diagrams which showed below:

Table (1) shows CT finding versus U/S in detection of affected side

\begin{tabular}{|l|l|l|}
\hline Affected side & U/S & CT \\
\hline Left & 6 & 13 \\
\hline Right & 6 & 4 \\
\hline Both & 10 & 14 \\
\hline Nill & 28 & 19 \\
\hline
\end{tabular}

Table (2) shows CT finding versus U/S in detection of site of the stone

\begin{tabular}{|l|c|c|}
\hline Site of the stone & CT & U/S \\
\hline Kidney & 22 & 18 \\
\hline Ureter & 9 & 4 \\
\hline Nill & 19 & 29 \\
\hline
\end{tabular}

Table(3) shows CT versus US in detection of stone according to size in the kidney

\begin{tabular}{|l|c|c|c|c|}
\hline Modality & $\begin{array}{c}\text { Less than } \\
5 \mathrm{~mm}\end{array}$ & More than 5mm & total & percentage \\
\hline U/S & 4 & 14 & 18 & $36 \%$ \\
\hline CT & 8 & 14 & 22 & $44 \%$ \\
\hline
\end{tabular}


Table(4) shows CT versus US in detection of stone according to size in the in the ureter

\begin{tabular}{|l|l|l|l|l|}
\hline Modality & Less than $5 \mathrm{~mm}$ & More than $5 \mathrm{~mm}$ & total & percentage \\
\hline U/S & 0 & 4 & 4 & $8 \%$ \\
\hline CT & 1 & 8 & 9 & $18 \%$ \\
\hline
\end{tabular}

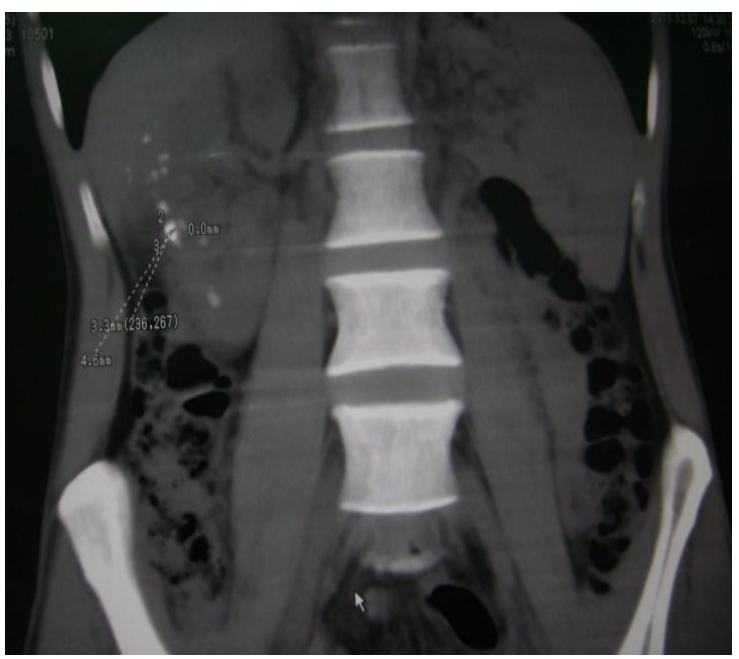

Figure (1) shows CT coronal section image with multi small stone the largest one is 3.3 X 4.6

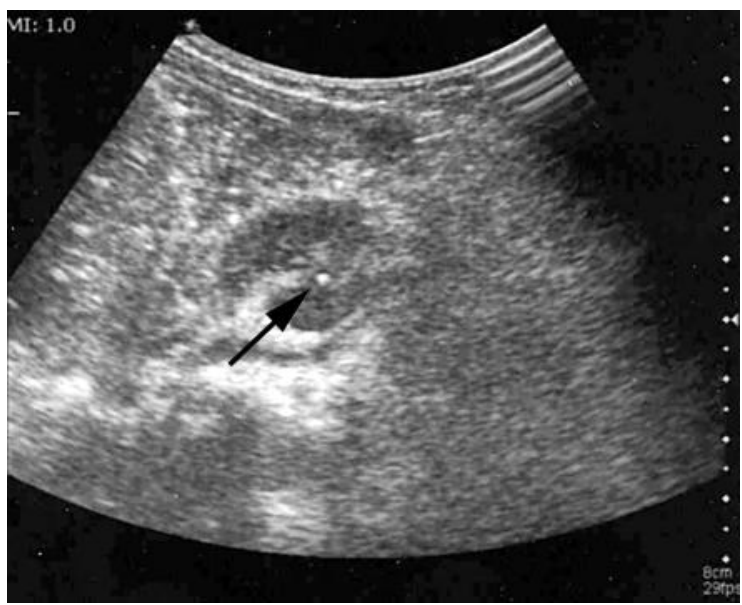

A

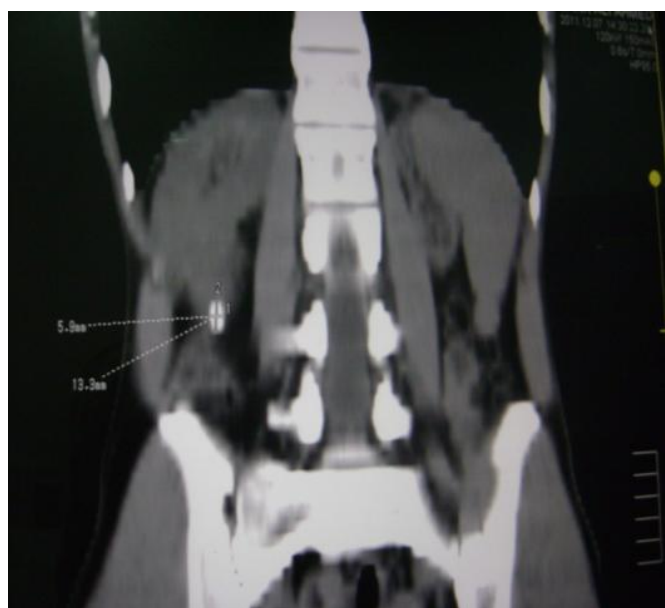

B

Figure (2) A-shows U/S finding of stone at Rt kidney lower pole

(B) Shows CT coronal section show Rt lower pole stone

\section{Discussion}


Recent studies have shown that non-contrast spiral CT is an excellent method for demonstrating renal stones in patients with suspected renal colic exactly identifying ureteral stones. In another comparative study done by Smergel et al, [4] noted that reformatted, non-contrast spiral CT images were superior to a combination of U/S and plain abdominal radiography for imaging ureteric calculi. In this study, a comparison was made between spiral CT and US in 50 patients, with comparable results for the two modalities in the demonstration of renal calculi. In some cases it was difficult to measure stone size by CT and U/S. The consecutive CT and U/S scanning of 50 patients were separated into urinary system and were evaluated; each image was analyzed separately. The present results agree with studied done by(Yilamz et al, and Oner et al) [5,6] 56\% of patients in studied sample are aged from 21-41 years old and they are mostly affected by renal stone, while $34 \%$ of patients are over 40 years U/S showed that both sides are affected equally, While CT findings showed that left sides were more affected than the right. U/S showed that $36 \%$ of total cases were affected with stones in the Kidney, while ureteric stones $(8 \%)$. U/S is non-invasive, inexpensive and radiation free, so it is preferred by some radiologists as the initial method for evaluation of the renal stones. However, U/S is considered to be of limited value in demonstrating pathological conditions of the ureter [7]. All patients with ureterolithiasis described had some degree of uretero-hydronephrosis, hence U/S was able to follow the ureter to the level of the stone and demonstrate the exact nature of the obstructing lesion. An intraluminal echogenic focus with acoustic shadowing was clearly depicted in all cases. Technical problems might occur in assessing the ureter when the stone is in the middle third, an area often obscured by bowel gas so this problem solved by compressing the area to be examined and changing the patient's position. Dalla Palma [8] evaluated 120 patients with renal colic using U/S and plain radiographs. U/S was classified as positive for ureteric colic in the study when calculi or hydronephrosis were present. In this study, CT and more sensitive in detecting renal calculi than U/S. In a study done by Sommer et al, there were false negative US examinations owing to a lack of significant hydronephrosis detectable on the examination [9].

\section{Conclusion}

Both spiral CT and U/S were found to be excellent modalities for depicting renal stones, CT and U/S are the first line of choice in diagnosis of renal calculi.

\section{References}

[1]. Teichman JM. Clinical practice. Acute renal colic from ureteral calculus. N Engl J Med. 2004;350:684-693.

[2]. Smith RC, Rosenfield AT, Choe KA, et al. Acute flank pain:comparison of non-contrast-enhanced CT and intravenous urography. Radiology. 1995;194:789-794.

[3]. Catalano O, Nunziata A, Altei F, et al. Suspected ureteral colic: primary helical CT versus selective helical CT after unenhanced radiography and sonography. AJR Am J Roentgenol. 2002;178: 379-387.

[4]. Smergel E., Greenberg S.B., Crisci K.L., Salven J.K.: CT urograms in pediatric patients with ureteral calculi: do adult criteria work? Pediatr Radiol, 2001, 31: 720-723.

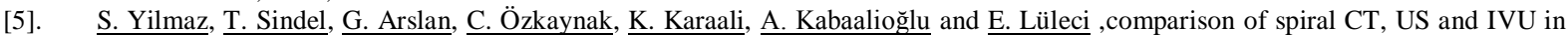
the detection of ureteral calculi, European Radiology Volume 8, Number 2, , 1997, 212-217

[6] S. Oner, A. Oto, S. Tekgul, M. Koroglu, M. Hascicek, A. Sahin and O. Akhan,Comparison of Spiral CT and us in the evaluation of pediatric urolithiasis, JBR-BTR, 2004, 87: 219-223

[7]. Myers M.T., Elder J.S., Sivit C.J., Applegate K.E.: Unenhanced helical CT in evaluation of urinary tract in children and young adults following urinary tract reconstruction: comparison with sonography. Pediatr Radiol, 2001, 31: 135-139.

[8]. Strouse P.J., Bates D.G., Bloom D.A.,Goodsitt M.M.: Non-contrast thin section helical CT of urinary tract calculi in children. Pediatr Radiol, 2002, 32: 326-332.

[9]. Niall O., Russell J., MacGregor R., Duncan H., Mullins J.: A comparison of noncontrast computerized tomography with excretory urography in the assessment of acute flank pain. J Urol, 1999, 161: 534-537. 